\title{
SOSIALISASI TOILET TRAINING DI DESA TABA BARU KECAMATAN TABA PENANJUNG KABUPATEN BENGKULU TENGAH
}

\author{
Toilet Training Socialization In The Village Of Taba Baru Kecamatan Taba Penanjung \\ Kabupaten Bengkulu Tengah \\ ${ }^{1)}$ Sri Saparahayuningsih, ${ }^{2)}$ Zahratul Qalbi, ${ }^{3)}$ Indrawati \\ 1,2.3 Pendidikan Guru Pendidikan Anak Usia Dini, Fakultas Keguruan dan Ilmu Pendidikan, \\ Universitas Bengkulu, \\ Email : zahratulqalbi@unib.ac.id
}

\begin{abstract}
ABSTRAK
Mitra pada kegiatan pengabdian ini adalah Desa Taba Baru Kecamatan Taba Penanjung, Kabupaten Bengkulu Tengah. Permasalahan pada kegiatan ini adalah masih minimnya pengetahuan orang tua tentang Toilet Training pada Anak Usia Dini. Solusi yang ditawarkan adalah memberikan sosialisasi kepada orang tua tentang pentingnya untuk mengetahui Toilet Training sejak dini agar anak-anak bisa mandiri untuk pergi ke toilet. Sosialisasi ini diberikan kepada orangtua sebanyak 24 orang. Kegiatan dilaksanakan pada hari Selasa tanggal 09 Juli 2019. Metode yang dipakai adalah ceramah dan diskusi. Melalui metode ini diharapkan ada peningkatan pemahaman peserta tentang Toilet Training Pada anak Usia Dini. Hasil dari pengabdian ini peningkatan pengetahuan masyarakat khususnya orang tua tentang pentingnya Toilet Training diajarkan pada anak sejak usia dini.
\end{abstract}

Kata Kunci : Sosialisasi, Toilet Training, Kebersihan, Anak Usia Dini

\section{ABSTARCT}

Partners in this dedication activity are Taba Baru Village, Taba Penanjung District, Bengkulu Tengah Regency. The problem in this activity is the lack of parental knowledge about Toilet Training in Early Childhood. The solution offered is to provide socialization to parents about the importance of knowing Toilet Training early so that children can be independent to go to the toilet. This socialization was given to as many as 24 parents. The activity will be held on Tuesday, July 9, 2019. The method used is lecture and discussion. Through this method, it is hoped that there will be an increase in the participants' understanding of Toilet Training in Early Childhood. The result of this dedication is increasing community knowledge, especially parents about the importance of Toilet Training taught to children from an early age.

Keywords : Socialization, Toilet Training, Cleanliness, Early Childhood

Diterima : 01-11-2020 Disetujui : 15-11-2020 Dipublikasikan : 30-12-2020 


\section{PENDAHULUAN}

Usia dini adalah usia anak dari mulai dalam kandungan sampai dengan usia masuk sekolah yaitu enam tahun. Golden age atau usia emas merupakan simbol dari pentingnya perkembangan anak sejak usia dini. Tidak ada yang boleh terlewatkan dalam proses pengajaran untuk pertumbuhan dan perkembangan anak di usia ini. Anak usia dini memiliki daya ingat dan daya serap informasi yang bagus. Untuk itu kesempatan bagi orang dewasa khusunya orang tua untuk mengoptimalkan perkembangannya. Sejak dini kita dapat mengajarkan segala hal sesuai dengan tahap pertumbuhannya.

Banyak hal yang harus diajarkan kepada anak sedini mungkin salah satunya adalah Toilet Training yaitu membiasakan anak untuk mampu sendiri buang air kecil dan buang air besar.

Anak bisa mandiri untuk buang air kecil maupun besar menjadi salah satu ciri kemandirian anak di usia dini, dan itu menjadi salah satu faktor penting menciptakan kemandirian anak. Toilet Training menjadi tantangan sendiri untuk orang tua maupun pengasuh. Berhasil tidaknya proses Toilet Training bukan hanya pada hasilnya saja tetapi juga pada prosesnya. Karena banyak pembelajaran yang didapatkan anak maupun orang tua baik dari segi kemandirian, kesehatan, kebersihan kesabaran dan penambahan kemampuan. Orang tua atau pengasuh harus sabar dalam proses mengajarkan Toilet Training pada anak, konsisten, melihat kesiapan anak dan tanpa paksaan.

Setiap anak memiliki usia yang berbeda dalam belajar Toilet Training, ada anak yang umur 18 bulan sudah mampu, ada yang lebih dari dua tahun baru bisa. Tidak ada usia pasti dalam memulai Toilet Training pada anak.

"Toilet Training merupakan salah satu usaha untuk melatih anak agar mampu mengontrol dan melakukan buang air kecil dan buang air besar. Salah satu aspek perkembangan yang umum dalam periode pra sekolah adalah pengajaran ke toilet sehingga anak sudah mampu menahan kandung kemih" (Rudolph \& Hoffman, 2006).

Kegagalan yang sering terjadi dalam proses Toilet Training seperti cara atau aturan yang ketat oleh orang tua kepada anaknya, anak akan cenderung menjadi keras kepala dan cepat emosi. "Hal ini sering dilakukan oleh orang tua apabila saat memarahi anak dalam latihan buang air kecil dan air besar. Bila orang tua santai dalam memberikan aturan dalam Toilet Training maka anak akan menjadi cenderung ceroboh dan seenaknya dalam melakukan kegiatan sehari-hari" (Hidayat, 2009).

Banyak faktor yang mempengaruhi berhasil tidaknya mengajarkan Toilet Training yaitu "motivasi orang tua dan kesiapan anak secara fisik, psikologis maupun secara intelektual menjelaskan bahwa motivasi orang tua sendiri dipengaruhi oleh faktor intrinsik dan faktor ekstrinsik. Faktor intrinsik merupakan dorongan yang berasal dari dalam diri seseorang yaitu berupa pengetahuan, sikap, keadaan mental dan kematangan usia sedangkan faktor ekstrinsik yaitu berupa sarana atau prasarana dan lingkungan" (Hidayat, 2009).

Membutuhkan persiapan baik dari segi fisik maupun mental anak dalam proses mengajarkan mandiri ke kamar mandi. Selain itu juga disbutuhkan kesabaran, pengertian dan kasih sayang terhadap anak leh orang dewasa. "Mengajari cara buang air yang paling mudah adalah ketika anak siap melaksanakan tahapan ini dan dia mau bekerja sama. Memulai sebelum anak siap hanya akan mengundang masalah dan sering menyebabkan kecelakaan dalam pemakaian toilet. Mengompol dan buang air besar di celana biasanya merupakan akibat dari ketidakmampuan anak mengenali dorongan untuk pergi ke toilet atau mengatur otot-otot pelepasan. Ini bukan usaha untuk melawan atau tanda ketidakpatuhan. Tampaknya anak juga akan frustasi jika dia tidak dapat melakukan seperti yang diharapkan" (Dowshen, 2002).

"Belajar untuk menggunakan toilet tidak bisa dilakukan sampai anak mampu dan ingin. Anak harus belajar mengenali apa kebutuhan tersebut, belajar menahan air 
besar atau kecil sampai dia berada di toilet, dan kemudian melepaskannya. Kebanyakan anak tidak siap baik secara fisiologis maupun psikologis untuk mencapai tahap tersebut sampai paling tidak pertengahan tahun kedua. Sebagian besar anak, tanpa memperhatikan waktu dimulainya usaha untuk berlatih menggunakan toilet, mampu melakukannya dengan benar pada usia dua setengah hingga tiga tahun. Semakin awal melatihnya bukan berarti akan lebih cepat berhasil, tetapi mengulur-ulur proses tersebut juga akan memberi kesempatan timbulnya konflik" (Mueser, 2008).

Menurut (A. S. \& Widajati, 2010) "kejadian masih buang air kecil secara tidak sengaja terjadi sekitar $30 \%$ anak berumur 4 tahun, $10 \%$ anak berumur 6 tahun, $3 \%$ anak berumur 12 tahun dan $1 \%$ anak berumur 18 tahun. Mengatasi hal ini, pengenalan kamar mandi dan toilet seharusnya dilakukan orangtua sejak usia lebih dini yaitu umur 1618 bulan. (Indiarti, 2008) menyebutkan bahwa sebagian besar anak yang dilatih sebelum usia 18 bulan baru dapat menguasai keahlian toilet traiing dengan sempurna saat dia berusia 4 tahun. Sebaliknya, sebagian besar anak yang dilatih sekitar usia 2 tahun dapat menguasainya dengan baik sebelum usia 3 tahun."

Menurut Rugolotto dalam (Hidayat, 2009) "berhasil atau tidaknya fase Toilet Training sangat berpengaruh terhadap perkembangan selanjutnya dari seorang anak yaitu kemampuan mengendalikan perkemihan dan pencernaan."

Beberapa tanda anak sudah siap Toilet Training menurut Ikatan Dokter Anak Indonesia (dr. Catharine M. Sambo, 2012) antara lain : "1) Ia mampu menirukan Anda dan menunjukkan rasa tertarik untuk belajar, misalnya mengikuti Anda ke kamar mandi, 2) Ia mampu mengembalikan benda-benda ke tempatnya, baik diminta ataupun tidak, 3) Ia mampu menunjukkan tanda kemandirian dengan berkata tidak, 4) Ia sudah mampu berjalan dan duduk dengan baik, 5) Ia mampu menyampaikan rasa ingin buang air (kecil atau besar), 6)Ia mampu melepas dan mengenakan pakaiannya."

Pembiasaan dan pengulangan dalam mengajarkan toilet training pada anak secara tidak langsung sudah menanamkan nilainilai karakter dalam kehidupan anak seperti yang dijelaskan oleh (Marlina, S., Qalbi, Z., \& Putera, 2020) bahwa penanaman nilainilai karakter diberikan melalui keteladanan, pembiasaan, dan pengulangan dalam kehidupan sehari-hari. Suasana dan lingkungan yang aman dan nyaman, perlu diciptakan dalam proses penanaman nilainilai karakter.

Dalam proses mengajarkan Toilet Training diperlukan perencanaan yang matang baik dari keluarga, orang tua, tempat penitipan anak ataupun anak itu sendiri. Sangat penting memperhatikan mood si anak ketika akan memulai mengajarkan buang air. Kenalkan dulu barang-barang disekitar kamar mandi, alat-alat kebersihan untuk menjaga kesehatan anak. Tentukan jam anak kira-kira biasanya buang air besar maupun buang air kecil. Untuk waktu pertama sangat wajar anak belum bisa. Bahkan setelah berkali-kalipun tidak semua anak langsung mampu. Intinya jangan pernah ada tekanan maupun paksaan terhadap anak.

Berdasarkan latar belakang permasalahan yang telah diuraikan maka dapat dirumuskan permasalahan dalam kegiatan ini, masih rendahnya pengetahuan tentang Toilet Training pada orang tua dan masyarakat, maka diberikan sosialisasi dan pemahaman tentang bagaimana pelaksanaan Toilet Training untuk anak usia dini.

Tujuan pengabdian masyarakat ini adalah untuk meningkatkan wawasan pengetahuan masyarakat Desa Taba Baru Kecamatan Taba Penanjung Kabupaten Bengkulu Tengah tentang Sosialisasi Toilet Training sejak usia dini.

\section{METODE KEGIATAN}

Metode dalam kegiatan pengabdian masyarakat ini dilakukan dengan dua langkah sebagai berikut : 1) Metode ceramah, Pada awal kegiatan peserta diberikan pertanyaan yang berhubungan dengan kebiasaan mengajarkan anak ke toilet. Bertujuan untuk mengetahui tingkat pemahaman peserta tentang Toilet Training sejak usia dini. 2) Metode diskusi, pada kegiatan ini orangtua dapat berkonsultasi 
dengan ahli dan berdiskusi secara langsung mengenai masalah yang terkait dengan anak. Pada akhir kegiatan orang tua diminta untuk diberikan tes yang sama seperti yang diberikan sebelum kegiatan dimulai.

Sasaran pengabdian masyarakat ini adalah "warga Desa Taba Baru Kecamatan Taba Penanjung Kabupaten Bengkulu Tengah" yang memiliki anak usia dini yang berjumlah 24 orang. Tempat dan waktu pengabdian masyarakat ini adalah bersamaan dengan kegiatan Kuliah Kerja Nyata (KKN) Mahasiswa Universitas Bengkulu yaitu pada tanggal 09 juli 2019 bertempat di Aula Kantor Desa Taba Baru Kecamatan Taba Penanjung Kabupaten Bengkulu Tengah.

\section{HASIL DAN PEMBAHASAN}

Lokasi pengabdian kepada masyarakat di lakukan di Desa Taba Baru Kecamatan Taba Penanjung, Kabupaten Bengkulu Tengah. Pemilihan lokasi di Desa Taba Baru bersamaan dengan kegiatan Kuliah Kerja Nyata (KKN) oleh mahasiswa Universitas Bengkulu Kelompok 114.

Desa taba baru merupakan salah satu dari 14 desa di wilayah Kecamatan Taba Penanjung Kabupaten Bengkulu Tengah, Desa Taba Baru mempunyai luas wilayah seluas $474 \mathrm{Ha}$. Adapun batas - batas wilayah desa Taba Baru Sebelah Utara berbatasan dengan Desa Taba Teret, Sebelah Selatan berbatasan dengan Desa Surau, Sebelah Timur berbatasan dengan Desa Rindu Hati, dan Sebelah Barat berbatasan dengan Sungai Air Sengak.

Iklim Desa Taba Baru, sebagaimana desa -desa lain di wilayah Indonesia mempunyai iklim tropis yaitu kemarau dan penghujan, hal tersebut mempunyai pengaruh langsung terhadap pola tanam yang ada di Desa Taba Baru Kecamatan Taba Penanjung Kabupaten Bengkulu Tengah.

Sebelum berdiri sebagai desa sendiri, Desa Taba Baru merupakan bagian dari Desa Taba Teret yang merupakan wilayah Kecamatan Taba Penanjung Kabupaten Bengkulu Tengah. Pada tanggal 17 Mei 2010 barulah Desa Taba Baru membentuk sebuah pemerintahan desa sendiri.
Nama Desa Taba Baru diambil dari nama Taba baru yang artinya dalam bahasa Rejang Tebas Baru dan terjadinya dalam bahasa Indonesia berarti Membuka Lahan Baru

Pengabdian kepada masyarakat ini dilaksanakan di kantor "Desa Taba Baru Kecamatan Taba Penanjung, Kabupaten Bengkulu Tengah." Judul kegiatan pengabdian kepada masyarakat ini adalah "Sosialisasi Toilet Training" Pelaksanaan kegiatan ini dihadiri warga Desa Taba Baru, Aparat Desa, dan Mahasiswa yang ikut dalam kegiatan KKN di Desa Taba Baru, serta beberapa Dosen Program Studi Pendidikan guru PAUD FKIP UNIB.

Acara pengabdian kepada masyarakat disambut dan dibuka langsung oleh Ibu Heppi Jaya selaku Kepala Desa Taba Baru Kabupaten Bengkulu Tengah.

Dalam sosialisasi kepada warga masyarakat desa Taba Baru tentang Toilet Training Anak Usia Dini, diawali dengan membentuk hubungan dan keakraban antara pemateri dengan peserta. Setelah itu dilakukan tanya jawab tentang yang berkaitan dengan Toilet Training.

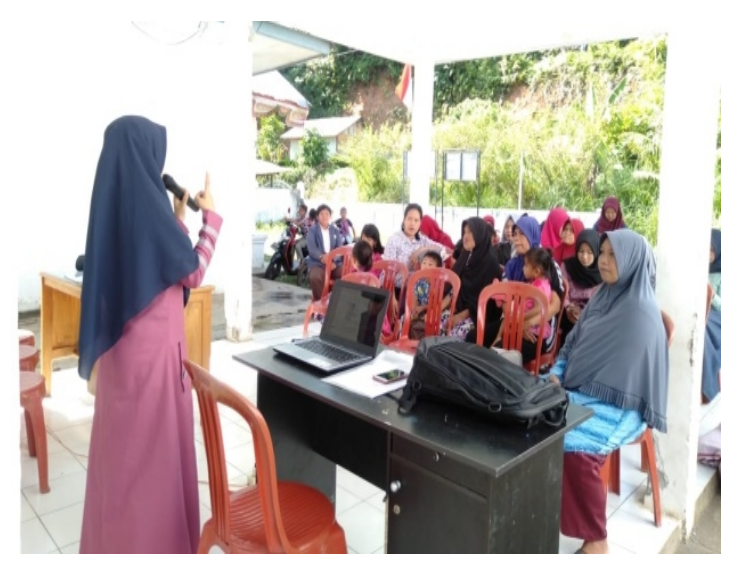

Gambar 1. Foto salah satu Pemateri sedang memberikan Sosialisasi Toilet Training 


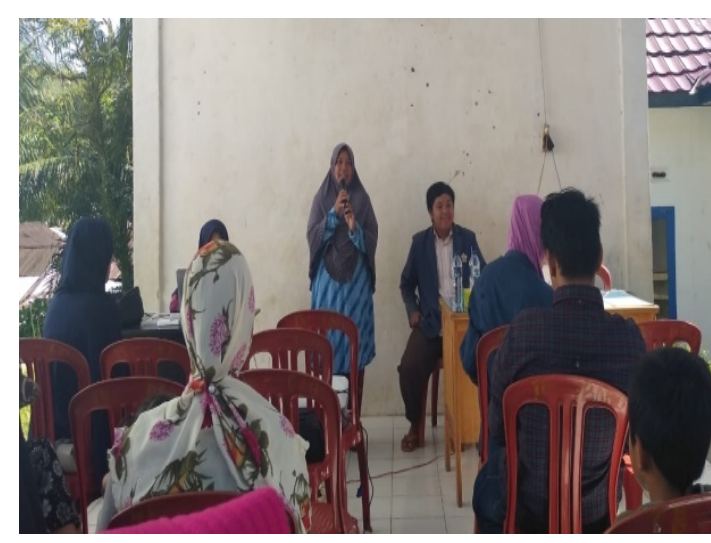

Gambar 2. Foto sambutan dari Kepala Desa Taba Baru Kab. Bengkulu Tengah Saat Acara Pembukaan Pengabdian Kepada Masyarakat

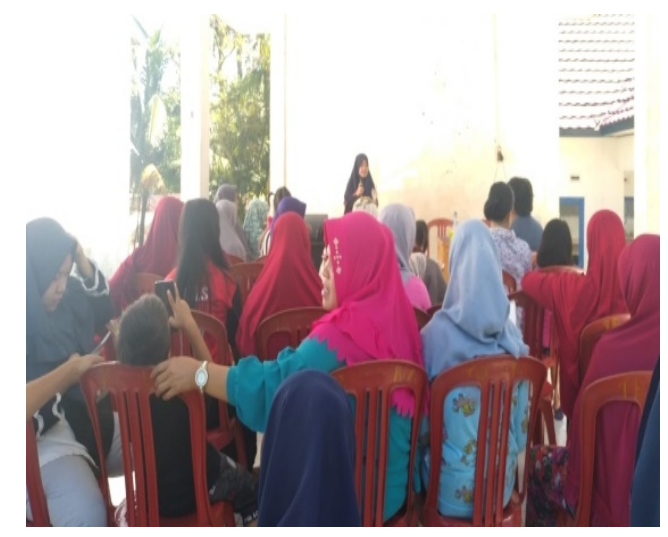

Gambar 3. Foto saat Sosialisasi Toilet Training

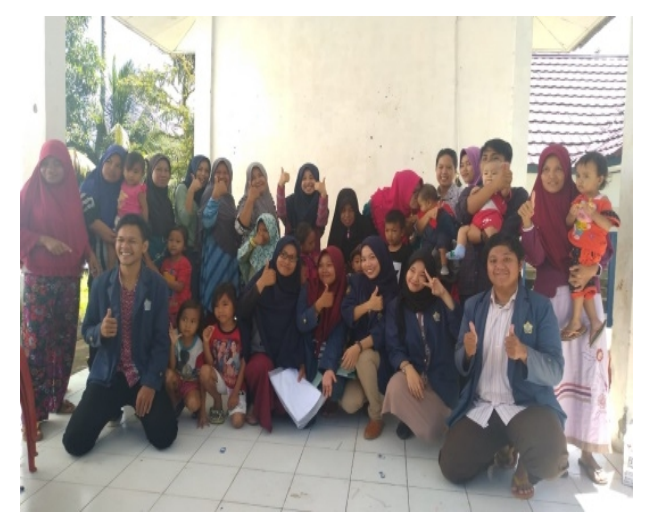

Gambar 4. Foto Bersama Tim Pengabdian dan Warga Desa Taba Baru setelah Sosialisasi

Hasil Kegiatan
Untuk mengetahui hasil kegiatan pengabdian kepada masyarakat ini, dilakukan wawancara kepada peserta tentang 1) apakah materi Toilet Training bermanfaat bagi bapak/ibu dalam mendidik anaknya di rumah? 2) apakah bapak/ibu sudah melaksanakan Toilet Training yang benar terhadap anak-anak dalam keluarga? 3) selama ini apa kendala yang dihadapi dalam mengajarkan Toilet Training kepada anak?

Hasil kegiatan pengabdian masyarakat tentang Sosialisasi Toilet Training terhadap Perkembangan Anak Usia Dini hasilnya adalah sebagai berikut:

Rata-rata orang tua sudah memahami pentingnya dan sudah melaksanakan Toilet Training yang benar, namun sering lupa sering tidak konsisten karena kurang sabar menunggu perubahan anak.

Ada beberapa hal yang belum dilaksanakan seperti mengajarkan membersihkan diri sesudah selesai dari kamar mandi, tidak melakukan secara bertahap, tidak konsisten dan menginginkan hasil yang instan.

\section{SIMPULAN}

Peserta yang hadir bertahan mengikuti kegiatan pengabdian ini sampai selesai. Rata-rata peserta sudah mengetahui tentang Toilet Training namun hanya berbeda istilah penyebutan dalam kehidupan sehari-hari. Hal yang masih belum bisa dilakukan adalah konsisten dalam mengajarkan anak untuk ke toilet, tidak melakukan secara bertahap dan menginginkan hasil yang instan.

\section{DAFTAR PUSTAKA}

A. S., S., \& Widajati, S. (2010). Hubungan Antara Motivasi Stimulasi Toilet Training Oleh Ibu Dengan Keberhasilan Toilet Training Pada Anak Prasekolah. Jurnal Penelitian Kesehatan Suara Forikes.

Dowshen, S. A. (2002). Panduan kesehatan balita petunjuk lengkap untuk orang tua. PT Raja Grafindo Persada.

dr. Catharine M. Sambo, S. . (2012). Toilet Training. 
https://www.idai.or.id/artikel/klinik/pe ngasuhan-anak/toilet-training

Hidayat, aziz alimul. (2009). Pengantar Ilmu Keperawatan Anak 1. In 1.

Indiarti, M. . (2008). Panduan lengkap kehamilan, persalinan dan perawatan bayi. Yogyakarta : Diglossia Media.

Marlina, S., Qalbi, Z., \& Putera, R. F. (2020). Efektivitas Kemerdekaan Belajar Melalui Bermain Terhadap Karakter Anak TK Baiturridha Kabupaten Padang Pariaman. Jurnal Ilmiah Potensia, 5(2), 83-90.

https://doi.org/https://doi.org/10.33369/ jip.5.2. 83-90

Mueser, A. M. (2008). Panduan lengkap perawatan bayi dan anak $A-Z$. Diglossia Media.

Rudolph, A. M., \& Hoffman, J. I. E. (2006). Buku ajar pediatri rudolph. Jakarta: $E G C$.

https://doi.org/10.1039/c7ra01024a 